\title{
Prenatal treatment with thyrotrophin releasing hormone to prevent neonatal respiratory distress
}

\author{
Francis de Zegher, Bernard Spitz, Hugo Devlieger
}

Three major strategies, that are not mutually exclusive, are being developed to tackle the problem of respiratory distress syndrome in preterm infants. The first is to prevent premature birth itself through improved obstetrical follow up and care; however, this has proved not to be an easy task. ${ }^{1}$ The second is to optimise the postnatal treatment of infants with respiratory distress through the availability of neonatal intensive care units and their motorised or airborne transportation teams, as well as through the use of novel medication and techniques, for example, the endotracheal administration of biosynthetic pulmonary surfactant, artificial ventilation with liquid or high frequency oscillation, and extracorporal membrane oxygenation. The third strategy is to administer, in cases of threatening premature birth, a treatment to the fetus that accelerates the fetal preparation for neonatal respiration, thus preventing the development of neonatal respiratory distress.

The concept of accelerating fetal maturation was launched in 1969, when Liggins noted as an epiphenomenon of his study on the initiation of parturition in the ewe that the infusion of dexamethasone had a stimulatory effect on the lung aeration of prematurely delivered lambs. ${ }^{2}$ This pioneering observation has now been repeatedly confirmed and has been extended to numerous mammalian species, including the human. In addition, the underlying pathophysiological mechanisms are increasingly well understood. ${ }^{3}$ The principle has been applied successfully in human perinatal medicine, where the administration of glucocorticoids to the pregnant woman-and thus transplacentally to the fetus-has served as the 'gold standard' of fetal maturational treatment for nearly two decades. ${ }^{45}$

The regulation of lung development during fetal life has been documented extensively to be under multihormonal control. ${ }^{3}$ Thyroid hormones in particular appear to stimulate fetal pulmonary maturation. However, as thyroid hormones and thyroid stimulating hormone (TSH or thyrotrophin) fail to cross the human placental barrier sufficiently, ${ }^{6}$ thyrotrophin releasing hormone (TRH) has become the prime focus of attention. ${ }^{7}$ There is evidence suggesting that TRH may also be useful in accelerating fetal maturation through its nonendocrine actions.

Thyrotrophin releasing hormone

In the search for hypothalamic hypophysiotropic peptides, a tripeptide stimulating the release of thyrotrophin by the mammalian anterior pituitary was the first hypothalamic releasing hormone to be structurally identified; this tripeptide, discovered in 1969, pyroglutamylhistidyl-proline amide, was designated TRH. ${ }^{8} 9$

TRH is the smallest of the known peptide hormones and appears to have ancient origins pre-existing its hypophysiotropic properties, as evidenced by the presence of TRH in the brain and neural ganglia of some invertebrate species lacking a pituitary gland. ${ }^{10}$

The neuronal biosynthesis of TRेH follows classical peptide synthesis pathways. The first post-transcriptional peptide, pre-pro-TRH, contains five repeating sequences coding for the tetrapeptide Gln-His-Pro-Gly with at least two flanking region peptides. Before entering axonal processes, pre-pro-TRH is cleaved into the tetrapeptide (pro-TRH). Finally, Gly is exchanged for a terminal amide, and TRH (packaged in storage granules) is ready for secretion. ${ }^{11}$

TRH has been localised in numerous regions of the mammalian nervous system. ${ }^{11}$ The classical TSH-regulating hypophysiotropic neurons originate from the paraventricular nucleus and project to the median eminence of the hypothalamus. ${ }^{11}$ TRH has been detected in the human fetal hypothalamus as early as 10-12 weeks' gestation and concentrations are thought to increase progressively towards term. ${ }^{13}$ TRH is present in the extrahypothalamic brain of the human fetus; it has been detected in the cerebellum as early as the ninth week of gestation. ${ }^{14}$ TRH has also been found in the nucleus tractus solitarius, which participates in the control of breathing; in vitro evidence strongly supports a role for TRH in the physiological regulation of rhythmic breathing in mammals. ${ }^{15}$ Other TRH-containing neurons include those localised in structures of the limbic system (effect on arousal), in a descending neural pathway from brain stem raphe nuclei projecting to spinal motor neurons (effect on muscle function) and those forming the intermediolateral column (cardiovascular effects). The mammalian placenta, ${ }^{16}$ retina, ${ }^{17}$ and male reproductive organs ${ }^{18}$ have also been reported to contain TRH. However, the most abundant presence of TRH in the developing mammal is found in the gastrointestinal system, particularly in the islets of the pancreas. ${ }^{17} 19-22$

TRH is subject to rapid enzymatic breakdown in tissues (including the anterior pituitary), serum and other body fluids, yielding several metabolites of uncertain physiological signifi-
Hevo Devlieger Professor de Zegher. 
cance. ${ }^{10}$ In the human adult, the pharmacokinetics of TRH are partly regulated by the thyroid status; in euthyroid conditions, the plasma half life of TRH is almost seven minutes. ${ }^{23}$ In pregnant women, the serum TRH degrading activity is lower than in euthyroid, non-pregnant adults. ${ }^{24}$ Intravenously infused TRH appears to be distributed exclusively in the extracellular fluid. ${ }^{23}$ The permeability of the blood-brain barrier to TRH is poor. ${ }^{25} \mathrm{TRH}$, in contrast to thyroxine and TSH, crosses the human placenta readily. ${ }^{6} 26$ The pharmacokinetics of TRH in the human fetus and newborn have not yet been reported. Raised plasma TRH concentrations, largely from extrahypothalamic origin, have been documented in the fetal rat and sheep at midgestation. ${ }^{19} 20$ The cord serum TRH concentration of the human infant at term birth is raised and falls within the days after birth. ${ }^{20}$ The TRH degrading activities in human fetal serum and in human neonatal cerebrospinal fluid are very low compared with adult standards. ${ }^{24} 27$

The TRH receptors localised in the pituitary, in the gastrointestinal tract, and in the nervous system resemble each other. ${ }^{28}{ }^{29}$ Although the latter are ubiquitously distributed, the highest densities are found in limbic structures, particularly the hypothalamus and the amygdala, in the brain stem, the cerebellum, and the grey matter of the spinal cord; lower densities are present in the dorsal roots and ganglia of the spinal cord. ${ }^{30}$ The TRH receptor has now been cloned and identified as a novel member of the family of transmembrane, $G$ protein coupled receptors. The expression of the TRH receptor is regulated in part by cell specific posttranscriptional mechanisms (mRNA stability) (M C Gershengorn. Presented at Endocrine Society Meeting, Washington, 1991). TRH can down regulate its own receptor through time and dose dependent mechanisms, resulting in cellular desensitisation to TRH (J Perlman, M C Gershengorn. Presented at Endocrine Society Meeting, Washington, 1991). ${ }^{30}$ Whereas pituitary recovery from TRH desensitisation occurs presumably within hours, animal studies indicate that complete neuronal recovery may be delayed for one week. ${ }^{31}{ }^{32}$ TRH binding to its receptor on the cell membrane stimulates a second messenger system, probably inositol triphosphate/diacylglycerol, which acts to increase intracellular free calcium by mobilisation from intracellular pools and by increasing transport via cell membrane calcium channels. ${ }^{33}$ In the thyrotrophs of the anterior pituitary, TRH stimulates secretion and glycosylation of TSH, but does not increase the production of mRNA for either the $\alpha$ or the $\beta$ subunit of TSH. ${ }^{34}$

There is virtually no direct evidence available regarding the maturation of human fetal TRH receptors. However, TRH has long been known to stimulate TSH secretion in the premature infant born at 20 weeks' gestation, indicating the presence of pituitary TRH receptors by this age. ${ }^{35}$ Subsequent studies revealed that the intravenous injection of TRH to the pregnant woman within three hours of delivery increases the cord blood concentration of TSH at term and preterm birth. ${ }^{26} 3637$ The human fetal TSH reponse to maternal administration of TRH was recently evaluated in utero between 25 and 37 weeks' gestation; this study demonstrated a striking fetal TSH response of up to $100 \mathrm{mU} / 1$ within $10-30$ minutes from the intravenous TRH injection. ${ }^{38}$ It is noteworthy that the TSH response of the third trimester human fetus to exogenous TRH is at least in the range of the TSH surge normally observed within the first hours after birth and presumably elicited by endogenous TRH of hypothalamic origin. ${ }^{39} 40$ In the human, maternal intravenous administration of TRH does not appear to influence fetal prolactin secretion. ${ }^{37}$

The fetal thyroid gland becomes increasingly responsive to endogenous TSH stimulation throughout the third trimester of pregnancy, as evidenced by gradually rising serum thyroxine concentrations in the face of relatively constant serum TSH concentrations. ${ }^{4142}$ Therefore, the TRH evoked TSH response is considered to be the principal mediator of the changes in fetal thyroid status that occur after-exposure to exogenous TRH. In the term human fetus, these changes include a significant rise in serum thyroxine concentrations within 60 minutes, ${ }^{26} 37$ as well as a doubling of the circulating triiodothyronine concentrations within 120 minutes from intravenous maternal TRH injection. $^{36}$ The increase of serum thyroxine is exclusively of fetal thyroidal origin, whereas the augmented concentrations of bioactive triiodothyronine are largely derived from thyroxine deiodination in fetal peripheral tissues. ${ }^{20}$ This deiodination activity has been correlated with the fetal serum concentration of endogenous cortisol and can be further stimulated by exogenous glucocorticoids. ${ }^{20} 43$ The TRH induced serum concentrations of thyroxine and tri-iodothyronine return to baseline concentrations within a few hours. ${ }^{26} 3136$

Thyrotrophin releasing hormone and fetal preparation for neonatal respiration

Normal neonatal respiratory function requires sufficient and orchestrated maturation of multiple fetal organs and systems. Exogenous TRH may influence fetal maturation either directly or indirectly, through its effect on the fetal thyroid axis. Here, we provide a synopsis of the documented actions of TRH and thyroid hormones on the different fetal factors known to be involved in the preparation for neonatal respiration.

(1) PULMONARY SURFACTANT

Pulmonary surfactant is a surface active material synthesised and secreted by the type II epithelial cells of the alveoli of mammalian lungs. It consists of various lipids and proteins, forming a phospholipid monolayer that stabilises the alveoli at low lung volumes, thus preventing collapse and allowing for normal respiration. Insufficient alveolar presence of surfactant in the newborn leads to the clinical picture of hyaline membrane disease, the most frequent cause of neonatal respiratory failure and the 
leading cause of morbidity and mortality in prematurely born infants. ${ }^{44}$

It has been conclusively demonstrated that tri-iodothyronine accelerates the synthesis of surfactant in the fetal lung, particularly the synthesis of the phosphatidylcholine fraction. Moreover, tri-iodothyronine has a potent additive effect on the capacity of glucocorticoids to enhance surfactant synthesis. The actions of both hormones on the type II alveolar cells are mediated by different receptors and proceed through different biochemical mechanisms (reviewed by Ballard ${ }^{44}$ ).

\section{(2) PULMONARY FLUID AND ION TRANSPORT}

The fetal lung is filled with a chloride rich fluid that is actively secreted by the pulmonary epithelium towards the pharynx, where it is either swallowed or propulsed outside the oral cavity, thus contributing to the amniotic fluid (reviewed by $S$ trang ${ }^{45}$ ). The intrapulmonary pressure exerted by lung fluid and modulated by the laryngeal sphincter seems to be an important stimulator of fetal lung growth. ${ }^{+6}+7$

Normally, fluid production is diminished and reabsorption augmented in the immediate perinatal period. This is the result of the combined decreases in alveolar tension and in lymphatic and capillary hydrostatic pressure, of the increases in transpulmonary pressure and in plasma colloid pressure, and-most importantly - of the activated sodium transport by alveolar epithelial cells. These forces promote movement of sodium ions and water from the alveolar space through the apical membrane of epithelial cells into the lung interstitium, and finally into the lymphatic and systemic circulation. Insufficient or delayed clearance of lung fluid at birth leads to the clinical picture of 'transient neonatal tachypnoea', the most frequent cause of respiratory distress in infants born at term. Current evidence indicates that the principal mediators of the perinatal shift in lung fluid and ion transport are the catecholamines, atrial natriuretic peptide, and possibly vasopressin. Thyroid hormones and glucocorticoids appear to play a pivotal part as their increasing serum concentrations during development are required to sensitise the fluid flux to catecholamines. ${ }^{48}$ Atrial natriuretic peptide has been shown to decrease fetal lung fluid production possibly through endocrine and pulmonary paracrine pathways. ${ }^{49}$ 50 The demonstration that tri-iodothyronine and glucocorticoids increase the synthesis of atrial natriuretic factor by the alveolar type II cells suggests a stimulating effect of both hormones on this aspect of fetal lung maturation. ${ }^{50}$

\section{(3) THE CARDIOVASCULAR SYSTEM}

At birth, the respiratory organ of the fetus, the placenta, is replaced by the lungs as the site of gas exchange. Moreover, metabolic and thermoregulatory activities increase, leading to a substantial rise in oxygen consumption. These respiratory adaptations are largely mediated by circulatory changes.

The switch in respiratory organ involves the constriction of the ductus arteriosus and a dramatic fall in pulmonary vascular resistance. Both these phenomena appear to be essentially the result of shifts in arachidonic acid metabolism involving lipoxygenase products (leukotrienes) and cyclo-oxygenase products (prostaglandins and thromboxane). ${ }^{51}$ Thyroid hormones facilitate the postnatal closure of the ductus arteriosus, as suggested by the raised incidence of patent ductus arteriosus in infants with congenital hypothyroidism. ${ }^{52}$ Glucocorticoids are also known to have a maturational effect on the ductus arteriosus, by decreasing the ductus' sensitivity to the relaxing action of prostaglandin $\mathrm{E}_{2} .{ }^{53}$

The fulfilment of the neonatal rise in oxygen demand is partly accomplished through a marked increase in cardiac output, which is in turn mainly mediated by augmented concentrations of circulating catecholamines acting on myocardial $\beta$ adrenergic receptors. To obtain the necessary $\beta$ adrenergic receptor availability, the presence of thyroid hormones appears to be crucial. ${ }^{54}$ Interestingly, the prenatal circulating thyroid hormone concentrations are more important than the postnatal concentrations for this vital adaptive function. ${ }^{55} \mathrm{~A}$ recent cardiotocographic study of the preterm human fetus has shown that the maternal administration of TRH increases within an hour the frequency of fetal heart rate accelerations and increases the fetal heart rate variability; increases in these two variables are currently considered as indicators of improved fetal well being (W Gyselaers et al, unpublished observations).

\section{(4) FETAL BREATHING, PULMONARY GROWTH,} AND RESPIRATORY MUSCLES

Intermittently, the fetus makes rapid and irregular breathing movements that are of a magnitude comparable with postnatal respiration. These breathing movements participate in the circulation of lung fluid within the respiratory tract and provoke periodic oscillations in the pulmonary transmural pressure, both of which contribute to normal growth of the fetal lungs. ${ }^{56}$

The breathing activity in utero is also important for adequate development of the diaphragm and the intercostal muscles. ${ }^{56}$ The fetal efforts of these respiratory muscles have a profound effect on the configuration of the neonatal chest wall and the condition of these muscles at birth largely determines the infant's potential for efficient ventilation, particularly when the infant is born prematurely. ${ }^{57}$

In the fetal lamb, the intravenous or intracerebroventricular administration of TRH elicits-apparently through non-endocrine pathways - a behavioural arousal with increased body and eye movements and provokes a marked stimulation of fetal breathing movements, which become continuous, faster, and deeper. ${ }^{58}$ These data have even led to the suggestion that the presumed surge in TRH secretion at birth plays a part in the switch from a fetal to a postnatal breathing pattern. ${ }^{58}$

The effect of TRH on breathing activity in the human fetus has not been reported. How- 
ever, the cardiotocographic study of the human fetus after administration of TRH to the pregnant woman provides indirect evidence for an effect of TRH on human fetal behaviour and breathing comparable with the effect observed in the fetal lamb (W Gyselaers et al, unpublished observations). Indeed, the reported increase in the frequency of fetal heart rate accelerations suggests an increase in fetal body movements, as $\mathbf{9 1 - 9 8 \%}$ of fetal heart rate accelerations are normally associated with fetal body movements. ${ }^{60} 61$ Similarly, the reported increase in fetal heart rate variability is suggestive of an increase in fetal breathing movements, as there is also a close and positive correlation between these two variables. ${ }^{60}$

\section{Conclusion and outlook}

The available neuroendocrine and physiological information provides a solid basis for the clinical evaluation of prenatal TRH treatment in the prevention of neonatal respiratory distress. The effects of prenatal TRH treatment are expected to be beneficial, in part because of their striking synergism with the maturational actions of glucocorticoids.

The first analyses of the ongoing clinical trials suggest a maturational effect of prenatal TRH treatment on top of the known favourable actions of prenatal glucocorticoid treatment (GC Liggins, personal communication). ${ }^{31}$ There are no reported studies examining the clinical effect of prenatal TRH treatment in the absence of concomitant glucocorticoid administration.

Further basic and clinical research is needed to establish firmly the combined treatment of glucocorticoids and TRH as the novel prenatal treatment of choice. This research will have to include studies examining the timing and dosage variables in the treatment schedules. In this way an optimal, dual treatment regimen could be developed.

1 Iams JD, Peaceman AM, Creasy RK. Prevention of prematurity. Semin Perinatol 1988;12:280-91.

2 Liggins GC. Premature delivery of foetal lambs infused with glucocorticoids. I Endocrinol 1969;45:515-23.

3 Ballard PL. Hormones and lung maturation. Monogr Endocrinol 1986;28:24-277.

4 Liggins GC, Howie RN. A controlled trial of antepartum glucocorticoid treatment for prevention of the respiratory distress syndrome in premature infants. Pediatrics 1972;50 515-25

5 Crowley P, Chalmers I, Keirse MJNC. The effects of corticosteroids administration before preterm delivery: an overview of the evidence from controlled trials. $\mathrm{Br} \mathcal{F}$ Obste Gynaecol 1990;97:11-25.

6 Vulsma T, Gons MH, De Vijlder JJM. Maternai-feta transfer of thyroxine in congenital hypothyroidism due to total organification defect or thyroid agenesis. $N$ Engl $\mathscr{T}$ Med 1989;321:13-6.

7 Moya FR, Gross I. Prevention of respiratory distress syndrome. Semin Perinatol 1988;12:348-58.

8 Burgus R, Dunn TF, Desiderio D, Ward DN, Vale W, Guillemin R. Structure moleculaire du facteur hypothalamique hypophysaire TRF d'origine ovine: evidence par spectrometre de masse de la sequence Pca-His-Pro-
$\mathrm{NH}_{2}$. Comptes Rendus Académie Sciences de Paris 1969;269: 1870-3.

9 Schally AV, Redding TV, Bowers CY, Barret YF. Isolation and properties of porcine thyrotropin-releasing hormone. $\mathcal{J}$ and properties of porcine thyro
Biol Chem 1969;244:4077-80.

10 Jackson IMD. Thyrotropin-releasing hormone. $N$ Engl $\mathcal{f}$ Med 1982;306:145-55.

11 Reichlin S. Neural functions of TRH. Acta Endocrinol (Copenh) 1986;276(suppl):21-33.

12 Morley JE. Extrahypothalamic thyrotropin releasing hormone (TRH)-its distribution and its functions. Lif Sci 1979;25:1539-50.

13 Kaplan SL, Grumbach MM, Aubert ML. The ontogenesis of pituitary hormones and hypothalamic factors in the human fetus: maturation of central nervous system regulation of
anterior pituitary function. Recent Prog Horm Res 1976;32: 101.

14 Winters AJ, Eskay RC, Porter JC. Concentration and distribution of TRH and LRH in the human fetal brain. 7 Clin Endocrinol Metab 1974;39:960-3.

15 Dekin MS, Richerson GB, Getting PA. Thyrotropin-releasing hormone induces rhythmic bursting in neurons of the hormone induces rhythmic bursting in neuro
nucleus tractus solitarius. Science 1985;229:67-9.

16 Shambaugh G III, Kubek M, Wilber JF. Thyrotropinreleasing hormone activity in the human placenta. $\mathcal{f}$ Clin Endocrinol Metab 1979;48:483-6.

17 Martino E, Seo H, Lernmark A, Refetoff S. Ontogenic patterns of thyrotropin-releasing hormone-like material in rat hypothalamus, pancreas and retina: selective effect of light deprivation. Proc Natl Acad Sci USA 1980;77:4345-8.

18 Pekary AE, Meyer NV, Vaillant C, Hershman JM. Thyrotropin-releasing hormone and a homologous peptide in the male rat reproductive system. Biochem Biophys Res Commun 1980;95:993-1000.

19 Engler D, Scanlon MF, Jackson IMD. Thyrotropin-releasing hormone in the systemic circulation of the neonatal rat is derived from the pancreas and other extraneural tissues. $\mathcal{f}$ Clin Invest 1981;67:800-8.

20 Fisher DA, Polk DH. Development of the thyroid. Clinical Endocrinology and Metabolism 1989;3:627-57.

21 Kawano H, Daikoku S, Saito S. Location of thyrotropinreleasing hormone-like immunoreactivity in rat pancreas. Endocrinology 1983;112:951-1.

22 Leduque P, Aratan-Spire S, Czernichow P, Dubois PM. Ontogenesis of thyrotropin-releasing hormone in human Ontogenesis of thyrotropin-releasing hormone

23 Iversen E. Pharmacokinetics of thyrotropin-releasing hormone in patients in different thyroid states. F Endocrinol 1991; 128:153-9.

24 Neary JT, Nakamura C, Davies IJ, Soodak M, Maloof F. Lower levels of TRH-degrading activity in human sera and in maternal sera than in the serum of euthyroid, non pregnant adults. $\mathcal{F}$ Clin Invest 1978;62:1-5.

25 Zlokovic BV, Segal MB, Begley DJ, Davson H, Rakic L. Permeability of the blood-cerebrospinal fluid and bloodbrain barriers to thyrotropin-releasing hormone. Brain Res 1985,358:191-9.

26 Roti E, Gnudi A, Braverman LE. The placental transport, synthesis and metabolism of hormones and drugs which affect thyroid function. Endocr Rev 1981;4:131-49.

27 Rao JK, Ponte E, Lopez A, Jayaraman A, Prasad C. Thyrotropin-releasing hormone metabolism is attenuated in the cerebrospinal fluid of the human neonate. Neuropeptides 1986;8:159-63.

28 Dettmar PW, Lynn AG, Metcalf G, Morgan BA. Brain TRH receptors are the same as pituitary receptors. $\mathcal{F}$ Pharm

29 Lotti VJ, Chang RSL, Cerino DJ, Kling PJ Veber DF, Nutt RF. Thyrotropin-releasing hormone in gut tissues resemble pituitary receptors. Neurosci Lett 1986;64:173-6.

30 Horita A, Carino MA, Lai H. Pharmacology of thyrotropinreleasing hormone. Annu Rev Pharmacol Toxicol 1986;26: 311-32.

31 Morales WJ, O'Brien WF, Angel JL, Knuppel RA, Sawai S. Fetal lung maturation: the combined use of corticosteroids and thyrotropin-releasing hormone. Obstet Gynecol 1989; 73:11-6.

32 Ogawa N, Mizuno S, Nukina U, Tsukamoto S, Mori A. Effect of chronic thyrotropin-releasing hormone (TRH) administration on TRH receptors and muscarinic cholinergic receptors in CNS. Brain Res 1983;263:348-50.

33 Gershengorn MC. Mechanism of thyrotropin-releasing hormone stimulation of pituitary hormone secretion. Annu Rev Physiol 1986;48:515-26.

34 Lippman SS, Amr S, Weintraub B. Discordant effects of thyrotropin (TSH) releasing hormone on pre- and post-
transitional regulation of TSH biosynthesis in rat pituitary. Endocrinology 1986;119:343-8.

35 Jacobsen BB, Andersen H, Dige Peterson H, Hummer L. Pituitary thyroid responsiveness to thyrotropin-releasing hormone in preterm and small for gestational age newborns. Acta Paediatr Scand 1977;66:541-8.

36 Moya F, Mena P, Heusser F, et al. Response of the maternal, fetal and neonatal pituitary-thyroid axis to thyrotropinreleasing hormone. Pediatr Res 1986;20:982-6.

37 Roti E, Gardini E, Minelli R, Bianconi L, Alboni A, Braverman LE. Thyrotropin releasing hormone does not stimulate prolactin release in the preterm human fetus. Acta Endocrinol (Copenh) 1990;122:462-6.

38 Thorpe-Beeston JG, Nicolaides KH, Snijders RJM, Butler J, McGregor AM. Fetal thyroid stimulating hormone response to maternal administration of thyrotropin releasing hormone. Am $\mathcal{f}$ Obstet Gymecol 1991;164:1244-5.

39 Fisher DA, Klein AH. Thyroid development and disorders of thyroid function in the newborn. $N$ Engl $\mathcal{F}$ Med 1981;304: thyroid

40 Roti E. Regulation of thyroid stimulating hormone (TSH) secretion in the fetus and neonate. $\mathcal{F}$ Endocrinol Invest 988;11:145-58.

41 Klein AH, Oddie TH, Parslow M, et al. Developmental changes in pituitary-thyroid function in the human fetus and newborn. Early Hum Dev 1982;6:321-30.

42 Thorpe-Beeston JG, Nicolaides KH, Felton CV, Butler J McGregor AM. Maturation of the secretion of thyroid hormone and thyroid-stimulating hormone in the fetus. $N$ Engl f Med 1991;324:532-6.

43 Osathanondh R, Chopra IJ, Tulchinsky D. Effects of dexamethasone on fetal and maternal thyroxine, triiodo- 
thyroxine, reverse triiodothyroxine and thyrotropin levels. 7 Clin Endocrinol Metab 1978;47:1236-9.

44 Ballard PL. Hormonal regulation of pulmonary surfactant. Endocr Rev 1989;10:165-81.

45 Strang LB. Solute and water transport across the pulmonary epithelium: a new chapter in lung physiology inaugurated
by Alfred Jost. Biol Neonate 1989;55:355-65.

46 Alcorn D, Adamson TM, Lambert TF, Maloney JR, Ritchie BC, Robinson PM. Morphological effects of chronic $\mathrm{BC}$, Robinson PM. Morphological effects of chronic
tracheal ligation and drainage in the fetal lamb lung. $\mathcal{F}$ Anat

7 Fewell JE, Hislop AA, Kitterman JA, Johnson P. Effect of tracheostomy on lung development in fetal lambs. $\mathcal{F} A p p l$ Physiol 1983;55:1103-8.

48 Ballard PL. Hormonal control of lung maturation. Clinical Endocrinology and Metabolism 1989;3:723-53.

49 Sherman DJ, Ross MG, Gore E, Castro R, Hobel CJ, Fisher DA. Ovine fetal lung fluid response to intravenous saline solution infusion: fetal atrial natriuretic factor effect. $A m \mathcal{F}$ Obstet Gynecol 1988;159:1347-52.

50 Matsubara M, Mori Y, Umeda Y, Oikawa S, Nakazato $H$, Inada $M$. Atrial natriuretic peptide gene expression and its secretion. Biochem Biophys Res Commun 1988;156:619-27.

51 Birk E, Iwamoto HS, Heymann MA. Hormonal effects on circulatory changes during the perinatal period. Clinical Endocrinology and Metabolism 1989;3:795-815.

52 Fernhoff PM, Brown AL, Elsas LJ. Congenital hypothyroidism: increased risk of neonatal morbidity results in delayed treatment. Lancet 1987; i:490-1.
53 Clyman RI, Mauray E, Roman C, Rudolph AM, Heymann MA. Glucocorticoids alter the sensitivity of the lamb ductus arteriosus to prostaglandin E2. ₹ Pediatr 1981;98:126-8.

54 Birk E, Rudolph AM, Roberts JM. Fetal thyroidectomy reduces postnatal myocardial beta-adrenergic receptor reduces postnatal myocardial beta-adrenergic receptor
responses in newborn lambs. Pediatr Res 1988;23:431A.

55 Breall JA, Rudolph AM, Heymann MA. Role of thyroid hormone in postnatal circulatory and metabolic adjusthormone in postnatal circulatory and

56 Dawes GS, Patrick JE. Fetal breathing activity. In: Nelso GH, ed. Pulmonary development: transition from intrauterine to extrauterine life. New York: Marcel Dekker, 1985:75.97. 57 Devlieger $\mathbf{H}$. The chest wall in the preterm infant. Leuven University of Leuven. 1987. (PhD thesis.)

58 Bennet L, Gluckman PD, Johnson BM. The central effect of thyrotropin-releasing hormone on the breathing movements and electrocortical activity of the fetal sheep. Pediatr Res 1988;23:72-5.

59 Umans JG, Umans HR, Szeto HH. Effects of thyrotropinreleasing hormone in the fetal lamb. Am $\mathcal{F}$ Obstet Gynecol 1986;155:1266-71.

60 Dawes GS, Visser GHA, Goodman JDS, Levine DC. Numerical analysis of the human fetal heart rate: modulation by breathing and movement. Am $\mathcal{f}$ Obstet Gynecol 1981; 140:535-44.

61 Sadovsky E, Rabinowitz R, Freeman A, Yarkoni S. The relationship between fetal heart rate accelerations, fetal 1984;149:187-9. 